\title{
Detection of penicillin tolerance in Streptococcus pyogenes
}

\author{
G. J. VAN ASSELT and R. P. MOUTON \\ Department of Medical Microbiology, University Hospital, PO Box 9600, 2300 RC Leiden, The Netherlands
}

\begin{abstract}
Summary. Three traditional assays were used to determine the minimal bactericidal concentration (MBC) and minimal inhibitory concentration (MIC) for Streptococcus pyogenes (group A streptococci) in two phases of growth and the time taken to kill the organisms. Three other methods were used for the determination of penicillin tolerance: a cell-lysis assay, the $\beta$-lactamase disk method and the replication method. Twenty strains, comprising penicillin-tolerant clinical isolates and two laboratory mutants, were used to evaluate the six tests. Results indicated that two groups of $S$. pyogenes can be distinguished-four highly tolerant and three moderately tolerant strains. The moderately tolerant strains were not recognised when rapidly growing instead of stationary cultures were used for the MBC and MIC determinations. The MBC/MIC ratio for tolerant strains was $>100$. Tolerance percentage ranged from 0.30 to 1.07 and 0.29 to 3.96 for cultures in the mid-logarithmic and stationary phases of growth, respectively. The cell-lysis assay, the $\beta$-lactamase disk method and the replication method may be used to screen for tolerance. Detection of high or moderate tolerance by determining the $\mathrm{MBC} / \mathrm{MIC}$ ratio for midlogarithmic or stationary cultures is recommended.
\end{abstract}

\section{Introduction}

Treatment failures of pharyngitis or tonsillitis caused by penicillin-tolerant group A (Streptococcus pyogenes) have been described ${ }^{1,2}$ but the results of the various studies of this phenomenon are difficult to compare because of differences in methodology and definition..$^{3-7}$ Tolerance to penicillin, namely, a significantly decreased bactericidal effect on the organisms, is often defined as the ratio of the minimal bactericidal concentration to the minimal inhibitory concentration (MBC/MIC ratio) being $\geqslant 32 .{ }^{8}$ The percentage of cfu of a strain resistant to the antibiotic is the alternative criterion of tolerance; there is a species-dependent break-point. ${ }^{9,10}$ Tolerance is the mean percentage of cfu that survive at a concentration of antibiotic at least 32 times the MIC, but this definition, adapted from that of Goessens et al. ${ }^{9}$ and Meylan et al., ${ }^{11}$ does not take into account the growth phase.

Because the results of conventional MBC determinations are subject to many factors that raise doubts about their value, ${ }^{12,13}$ the bactericidal effects of penicillin in the mid-logarithmic and stationary phases of growth were compared with the results of a time-kill assay and an assay to measure the lytic response of

Received 20 Aug. 1992; accepted 28 Aug. 1992.

* Present address to which correspondence should be sent: Westeinde Hospital, Lijnbaan 32, 2512 VA Den Haag, The Netherlands. cells to penicillin. Six different procedures were analysed to determine which method or combination of methods can be used to detect penicillin tolerance in group A streptococci. Tolerance of group A streptococci in this study was defined as an MBC/MIC ration $\geqslant 32$ and a tolerance percentage of $\geqslant 0.2 \%$.

\section{Materials and methods}

\section{Bacterial strains}

Twenty $S$. pyogenes strains comprising 18 clinical isolates and two laboratory mutants, including one tolerant mutant from our laboratory, were used. Nine of these have been described previously as penicillintolerant. ${ }^{10,14,15}$ The other strains were clinical isolates. Streptococci were identified by the Streptex test (Wellcome Diagnostics, Dartford), bacitracin sensitivity and API-20 Strep (bioMérieux, La Balme les Grottes, France). Strains were lyophilised, stored and then subcultured once or twice on blood agar plates before use.

\section{Media, antibiotics and $\beta$-lactamase}

Streptococci were usually incubated in Todd-Hewitt Broth (THB, Oxoid) and on Blood Agar Base, Oxoid with defibrinated sheep blood (BioTrading, Wilnis, The Netherlands) $5 \%$, but in some experiments blood agar plates containing $0.25 \mathrm{U}$ of $\beta$-lactamase I from Bacillus cereus (Genzyme, Biochemicals Ltd, Maidstone, Kent) were used. Stock suspensions of pot- 
assium benzylpenicillin (Gist-Brocades, Delft, The Netherlands) were prepared immediately before use. Disks containing benzylpenicillin $10 \mu \mathrm{g}$ were obtained from BBL (Beckton Dickinson, Cockeysville, MD, USA). Disks containing $50 \mathrm{U}$ of $\beta$-lactamase I from $B$. cereus were freshly prepared.

\section{Growth curces}

Three methods were used to obtain cultures in the mid-logarithmic phase of growth:

For the first method, 5-10 colonies of an overnight culture of $S$. pyogenes were suspended in $10 \mathrm{ml}$ of THB and incubated overnight at $37^{\circ} \mathrm{C}$. This culture was seeded into $10 \mathrm{ml}$ of pre-warmed THB to an optical density ( $O D_{540}$, Vitatron) of $0 \cdot 1$, which corresponded to $c .2 \times 10^{7} \mathrm{cfu} / \mathrm{ml} ; 50 \mu$ lof the suspension was inoculated into $10 \mathrm{ml}$ of pre-warmed THB and incubated at $37^{\circ} \mathrm{C}$ with constant shaking. Samples were then taken regularly.

In the second method, $S$. pyogenes colonies from an overnight culture were suspended in $4 \mathrm{ml}$ of THB to obtain an $\mathrm{OD}_{540}$ of $0.1 ; 100 \mu 1$ of this suspension was seeded into $10 \mathrm{ml}$ of THB and incubated at $37^{\circ} \mathrm{C}$ with constant shaking. Samples were then taken regularly.

Thirdly, 5-10 colonies from an overnight culture of $S$. pyogenes were suspended in $10 \mathrm{ml}$ of THB and incubated at $37^{\circ} \mathrm{C}$ with constant shaking. At an $\mathrm{OD}_{540}$ of $0.06,1 \mathrm{ml}$ of this suspension was inoculated into $9 \mathrm{ml}$ of pre-warmed THB; after re-incubation at $37^{\circ} \mathrm{C}$ with constant shaking samples were taken regularly.

\section{MIC determinations}

Mid-logarithmic growth phase. MICs of penicillin for colonies in the mid-logarithmic growth phase were determined by adding an inoculum of $5 \times 10^{5} \mathrm{cfu} / \mathrm{ml}$ to $2 \mathrm{ml}$ of THB. Penicillin concentrations in two-fold dilutions ranged from 0.004 to $10 \mu \mathrm{g} / \mathrm{ml}$. To obtain mid-logarithmic cultures, 5-10 colonies of an overnight culture were grown in THB at $37^{\circ} \mathrm{C}$ with constant shaking. At an $\mathrm{OD}_{540}$ of 0.06 the cultures were diluted 1 in 10 in pre-warmed THB and reincubated until an OD of 0.06 was reached. The MIC tubes were inoculated with a 1 in 15 dilution of the culture. The inocula were carefully introduced below the broth surface to avoid contamination of the vessel walls and then mixed gently. Tubes were mixed again $4 \mathrm{~h}$ before and at the time of MBC plating. The MIC was defined as the lowest concentration of the antibiotic that prevented visible growth.

Stationary growth phase. To obtain stationary cultures, cells were incubated in THB at $37^{\circ} \mathrm{C}$ with constant shaking for $18 \mathrm{~h}$. The tubes were inoculated with a 1 in 60 dilution of the cultures. The handling of inocula and tubes was as described above.

\section{$M B C$ determinations and definitions}

The number of surviving organisms in each dilution tube showing no visible growth after incubation with penicillin for $24 \mathrm{~h}$ was determined. Fifty- and $100-\mu \mathrm{l}$ volumes were spread, directly or after appropriate dilution, on blood agar plates containing $0.25 \mathrm{U} \beta$ lactamase I from $B$. cereus. After incubation at $37^{\circ} \mathrm{C}$ for $48 \mathrm{~h}$, colonies were counted. The MBC was defined as the lowest antibiotic concentration that killed $>99.9 \%$ of the initial inoculum after incubation for $24 \mathrm{~h}$. In addition, the percentage of surviving cells at each penicillin concentration was determined.

\section{Time-kill assay}

Cells were prepared as described above for MIC determinations in the mid-logarithmic growth phase; an inoculum of $5 \times 10^{5} \mathrm{cfu} / \mathrm{ml}$ was used. Samples were taken after incubation for $0,2,4$ and $6 \mathrm{~h}$ from tubes containing $0 \cdot 25,2$ and $10 \mu \mathrm{g}$ penicillin $/ \mathrm{ml}$. A reduction in cfu of $<2 \log _{10}$ after incubation for $6 \mathrm{~h}$ with penicillin was taken as an indication of tolerance.

\section{Cell-lysis assay}

Cell lysis was determined by measuring the optical density $\left(O_{540}\right)$ of fast-growing cells (prepared as described above). THB cultures $(10 \mathrm{ml})$ with an $\mathrm{OD}_{540}$ of 0.06 were incubated with constant shaking at $37^{\circ} \mathrm{C}$ until an $\mathrm{OD}_{540}$ of 0.2 was reached. Penicillin was then added to obtain a concentration of $0.05-100 \mu \mathrm{g} / \mathrm{ml}$; one tube without penicillin was included as a control. After re-incubation the $\mathrm{OD}_{540}$ was measured every $20-60 \mathrm{~min}$. The reduction in $\mathrm{OD}_{540}$ of fast-growing cultures in THB after incubation for $6 \mathrm{~h}$ with $10 \mu \mathrm{g}$ penicillin $/ \mathrm{ml}$ is expressed as a percentage of the maximum OD reached. A non-lytic response is defined as $<30 \%$ reduction in $\mathrm{OD}_{540}$.

\section{The $\beta$-lactamase disk method}

A modification of the methods of Dankert et al. ${ }^{16}$ and Slater and Greenwood ${ }^{17}$ was used. Blood agar plates were inoculated with bacteria from an overnight culture to achieve semi-confluent growth. A disk containing $10 \mu \mathrm{g}$ of benzylpenicillin was placed in the centre of the plate. After incubation for $24 \mathrm{~h}$ at $37^{\circ} \mathrm{C}$ the penicillin disk was replaced by a freshly prepared disk containing $50 \mathrm{U}$ of $\beta$-lactamase I. After reincubation for $48 \mathrm{~h}$ colonies that developed around the disk in the central part of the former inhibition zone were counted and growth of $>10$ colonies was taken to indicate tolerance.

\section{The replication method}

A modification of the method of Kim and Anthony ${ }^{18}$ was used. Overnight cultures on blood agar plates were transferred with a swab to a blood agar layer that contained a penicillin gradient of $0-10 \mu \mathrm{g} / \mathrm{ml}$, freshly prepared by means of an agar overlay technique. After incubation at $37^{\circ} \mathrm{C}$ for $24 \mathrm{~h}$ a stamp covered with sterile velvet was pressed on to the plate and replicated on to an antibiotic-free blood agar plate. After incubation for $48 \mathrm{~h}$ at $37^{\circ} \mathrm{C}$ the number of growing colonies on the replicate plate was counted 

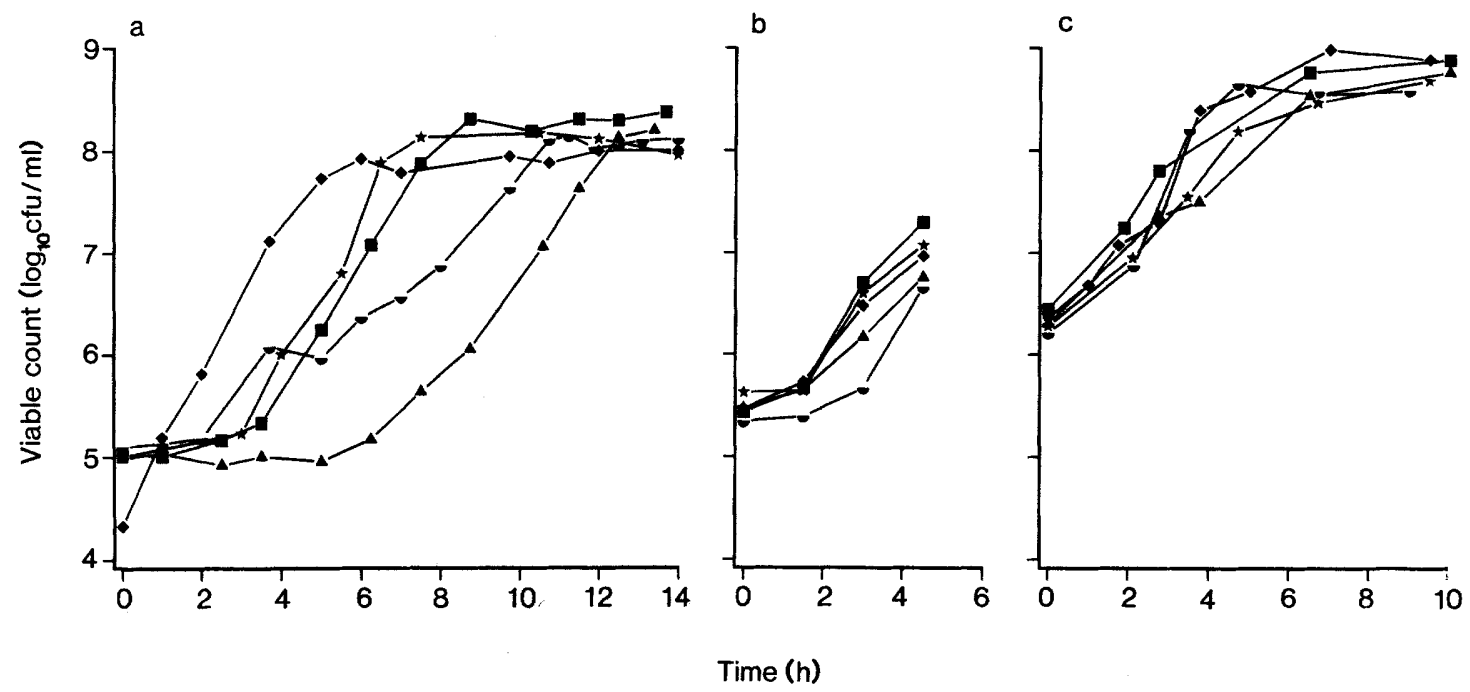

Fig. 1. Growth curves for five representative strains of $S$. pyogenes. Growth was measured in cfu/ml as a function of time (h). Figs. a, b and c represent growth patterns obtained with methods 1,2 and 3 , respectively.

and the area of growth recorded. Colonies located within the area on the replicate plate that corresponded to the area of highest concentration on the penicillingradient plate, the "superinhibitory" area, were transferred with a swab to a penicillin-gradient plate. After incubation at $37^{\circ} \mathrm{C}$ for $24 \mathrm{~h}$ the gradient plates were again replicated on to a blood agar plate. This procedure was repeated 15 times allowing the detection of growth after each transfer to the penicillingradient plate. (The replication value represents the number of successful consecutive transfers of colonies from the superinhibitory area on the replicate plates multiplied by the mean number of surviving colonies on the replicate plates.)

\section{Statistical analysis}

Separate or pooled data from each test were subjected to an analysis of variance. The Sheffé test was used only for the lysis assay. The data on all methods were subjected to the correlation analysis of Pearson. Statistical analysis was performed with the computer programme SPSS $/ \mathrm{PC}+4 \cdot 0$.

\section{Results}

\section{Growth curve studies}

A fixed incubation time for all strains, often used for tolerance assays, did not ensure the same degree of growth for each strain (figs. la and b), accordingly, the third method (fig. 1c) was selected. Mid-logarithmic phase cultures were obtained by measuring the growth of individual strains until an $\mathrm{OD}_{540}$ of 0.06 was reached. This method yielded the most reproducible results and guaranteed that the cells were in the midlogarithmic phase.

\section{$M B C$ and $M I C$ determinations}

All group A streptococci were susceptible to penicillin $\left(\mathrm{MIC}_{90} 0.016 \mu \mathrm{g} / \mathrm{ml}\right)$. MBC values, determined

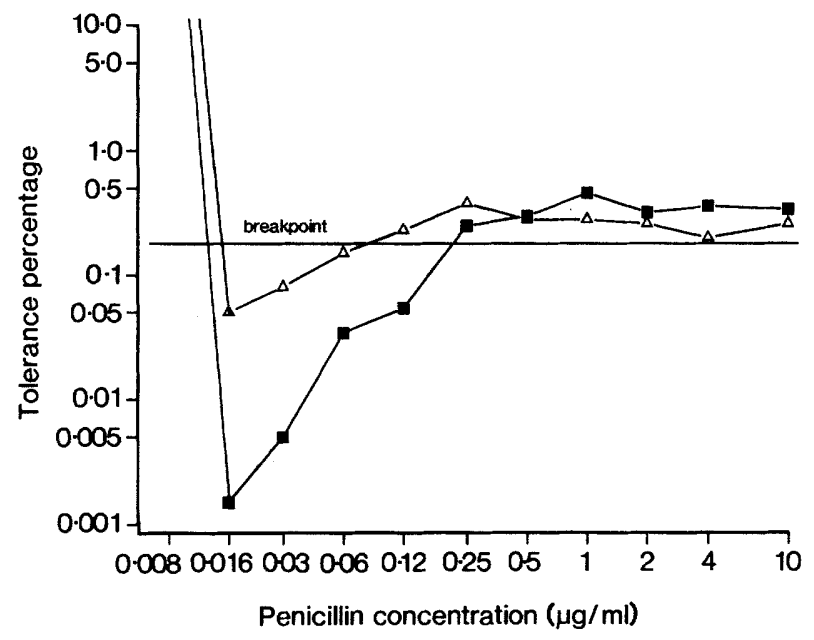

Fig. 2. Survival percentages for the initial inoculum in the midlogarithmic ( $\square)$ and stationary $(\triangle)$ phases of growth of a representative tolerant strain of $S$. pyogenes (strain 162; at isolation: $\mathrm{MIC}=0.016 \mu \mathrm{g} / \mathrm{ml}$ ) as a function of the penicillin concentration.

for two phases of growth, distinguished three sets of strains. Four had high MBC/MIC ratios $(>100)$ in both the mid-logarithmic and the stationary phase of growth. Three strains had equally high MBC/MIC ratios in the stationary phase only. The tolerance percentage for resistant isolates ranged from 0.30 to 1.07 and from 0.29 to 3.96 in the mid-logarithmic and stationary phases of growth, respectively; the differences were not significant. None of the remaining strains was tolerant.

The survival rate for the seven tolerant strains was at its lowest at penicillin concentrations just above the MIC. Killing at higher concentrations of penicillin was less effective (fig. 2).

\section{Time-kill assay}

Reproducible results were obtained in the kill assay for cultures incubated for $6 \mathrm{~h}$ with penicillin $0 \cdot 25,2$ or $10 \mu \mathrm{g} / \mathrm{ml}$ (table I). At $10 \mu \mathrm{g} / \mathrm{ml}$ concentration, five 
Table I. Reproducibility of results of the kill assay after incubation for $6 \mathrm{~h}$ of a penicillin-tolerant (162) and a nontolerant (105) strain of $S$. pyogenes at different concentrations of penicillin

\begin{tabular}{cc|ccc}
\hline \multirow{2}{*}{$\begin{array}{c}\text { Strain } \\
\text { no. }\end{array}$} & $\begin{array}{c}\text { Number } \\
\text { of } \\
\text { tests }\end{array}$ & \multicolumn{3}{|c}{$\begin{array}{c}\text { Mean delta } \log _{10} \text { cfu (SD) at } \\
\text { penicillin concentration }(\mu \mathrm{g} / \mathrm{ml})\end{array}$} \\
\cline { 3 - 5 } & 5 & 0.25 & 2 & 10 \\
\hline 162 & $5.66(0.13)$ & $0.57(0.14)$ & $0.67(0.15)$ \\
105 & 5 & $4.07(0.51)$ & $3.64(0.66)$ & $4.03(0.34)$ \\
\hline
\end{tabular}

Table II. Bactericidal effect of penicillin $10 \mu \mathrm{g} / \mathrm{ml}$ after incubation for $6 \mathrm{~h}$

\begin{tabular}{lc|cc}
\hline Strains & $\mathrm{n}$ & $\begin{array}{c}\text { Mean delta } \log _{10} \text { cfu } \\
\text { (SD) }\end{array}$ & Range \\
\hline Tolerant & 5 & $1 \cdot 03(0.37)$ & $0 \cdot 67-1 \cdot 48$ \\
Non-tolerant & 5 & $3 \cdot 12(0.46)$ & $2 \cdot 29-3 \cdot 60$ \\
\hline
\end{tabular}

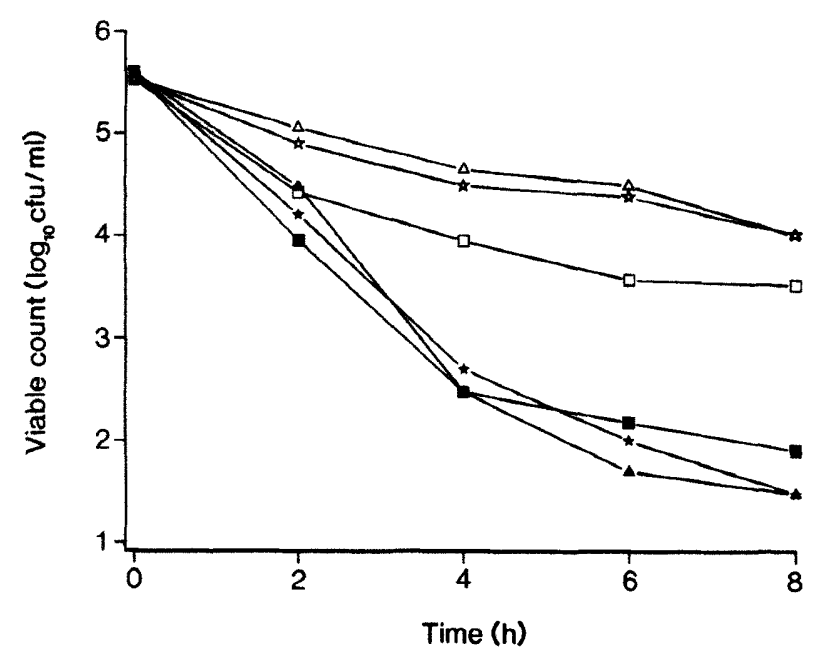

Fig. 3. Time-kill curves for $S$. pyogenes (strain 976, open symbols; strain 105, closed symbols). Bacterial kill in the presence of benzylpenicillin $(\mathbb{R}, 0.25 \mu \mathrm{g} / \mathrm{ml} ; \Delta .2 .0 \mu \mathrm{g} / \mathrm{ml} ;, 10.0 \mu \mathrm{g} / \mathrm{ml})$ is expressed in $\mathrm{cfu} / \mathrm{ml} / \mathrm{h}$. strains were not effectively killed (table II). For these tolerant strains a concentration of penicillin $0.25 \mu \mathrm{g} / \mathrm{ml}$ was the most effective bactericidal concentration (fig. 3).

\section{Cell-lysis assay}

The lytic effect of various concentrations of penicillin on rapidly growing cultures is shown in fig. 4 . In non-tolerant strains the reduction in optical density reached a maximum at a penicillin concentration of 4 or $10 \mu \mathrm{g} / \mathrm{ml}$; thus cell lysis increased as concentrations of penicillin were raised, but a further increase in the penicillin concentration had no additional effect. A concentration of $10 \mu \mathrm{g} / \mathrm{ml}$ was subsequently used for all lysis experiments. Seven tolerant strains and one slow-growing laboratory mutant exhibited a non-lytic response $(p<0.005)$. The mean reduction in optical density for these strains was $14.25 \% \quad(\mathrm{SD}=6.33)$ whereas the mean optical density reduction was $46.33 \%$ (SD $=11 \cdot 73$ ) for the non-tolerant strains.

\section{The B-lactamase disk method}

Seven tolerant strains gave positive results in the $\beta$-lactamase disk method. Four highly tolerant strains produced 75-225 colonies that grew around the disk and the three moderately tolerant strains produced 23-35 such colonies. None of the remaining strains gave reproducible positive results.

\section{The replicate method}

The replication potency, a factor calculated from the number of surviving colonies on the replicate plates multiplied by the number of successful consecutive passages, was related to the degree of tolerance of $S$. pyogenes. The non-tolerant strains did not replicate after consecutive transfer on to penicillin gradients except for three strains that had a maximum of two replications. Most tolerant strains replicated after each of the 15 transfers.
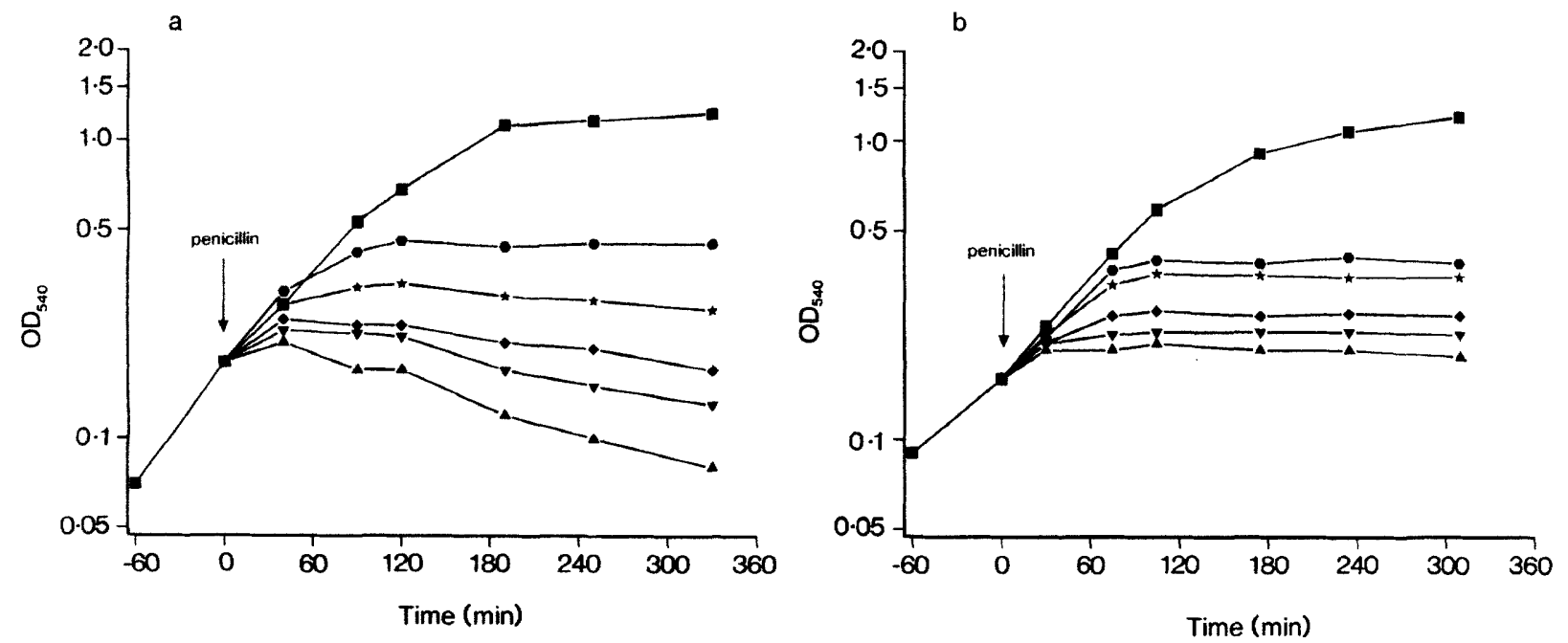

Fig. 4. Measurement of the optical density of fast-growing cells by cell-lysis assay as a function of time after the addition of penicillin $(\boldsymbol{G}$, control;, $0.12 \mu \mathrm{g} / \mathrm{ml} ;, 0.25 \mu \mathrm{g} / \mathrm{ml} ; \diamond, 0.5 \mu \mathrm{g} / \mathrm{ml} ; \nabla, 1.0 \mu \mathrm{g} / \mathrm{ml} ; \Delta, 4.0$ and $10.0 \mu \mathrm{g} / \mathrm{ml}$ ). (a), non-tolerant strain $977 ;(\mathrm{b})$, tolerant strain 301 . 


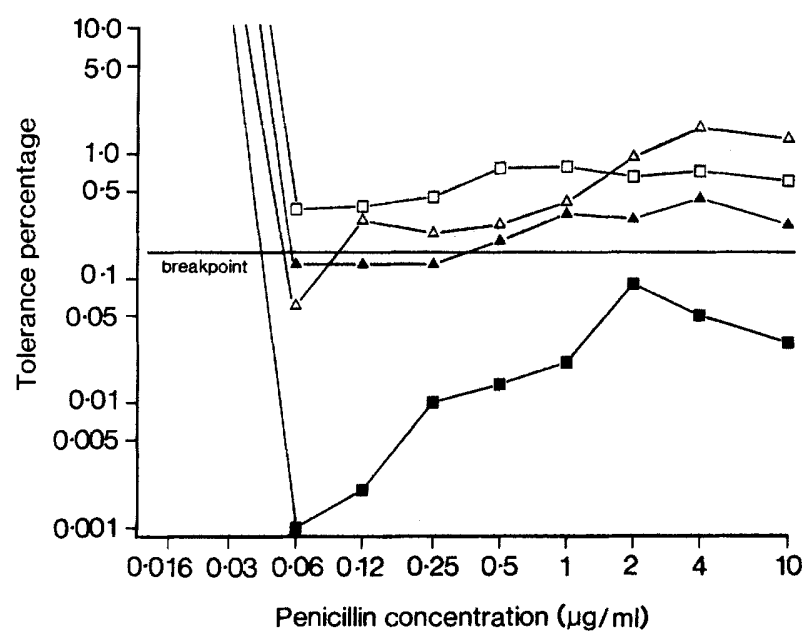

Fig. 5. Survival percentages for the initial inoculum in the midlogarithmic $(\boldsymbol{\Delta}, \square)$ and stationary $(\triangle, \square)$ phases of growth of a tolerant strain of $S$. pyogenes as a function of the penicillin concentration; $\square, \boldsymbol{\square}$, at isolation; $\triangle, \boldsymbol{\Delta}$, after exposure to penicillin gradients.

Table III. Comparison of six methods for detection of penicillin tolerance

\begin{tabular}{|c|c|c|c|c|}
\hline \multirow{3}{*}{$\begin{array}{c}\text { Methods } \\
\text { MBC/MIC in mid-logarithmic phase }\end{array}$} & \multicolumn{4}{|c|}{$\begin{array}{c}\text { Patterns of results obtained } \\
\text { with }\end{array}$} \\
\hline & \multicolumn{4}{|c|}{$\begin{array}{c}\text { Known tolerant } \\
\text { strains } \\
\text { (Number of strains) }\end{array}$} \\
\hline & $+^{*}$ & - & - & - \\
\hline $\mathrm{MBC} / \mathrm{MIC}$ in stationary phase & + & + & + & - \\
\hline Time-kill assay & + & + & - & - \\
\hline Cell-lysis assay & + & + & +-1 & - \\
\hline$\beta$-lactamase disk method & + & + & $+\quad-$ & - \\
\hline Replication method & $\begin{array}{c}+ \\
(4)\end{array}$ & $\begin{array}{c}+ \\
(1)\end{array}$ & $\begin{array}{cc}+ & - \\
(2) & (3)\end{array}$ & $(\overline{10})$ \\
\hline
\end{tabular}

* Non-reproducible $\mathrm{MBC}$ results for one strain.

† One slow-growing laboratory mutant produced no lysis.

Penicillin tolerance which was lost after storage could be restored by consecutive transfer of strains on to penicillin gradients (fig. 5). Tolerance for such strains increased slowly with each transfer to a penicillin gradient.

\section{Comparison of methods}

The combined results of all methods are given in table III. Seven documented strains were tolerant and could be classified as "highly tolerant" (four strains with all methods positive) or "moderately tolerant" (three strains with at least four methods positive and a high MBC/MIC ratio in the stationary phase only). None of the remaining strains showed any signs of tolerance, with the exception of one slow-growing laboratory mutant that had a non-lytic reaction only. Therefore, three of 10 documented tolerant strains were not tolerant.

Results obtained with the six methods were analysed to assess any correlations. There were significant correlations between the kill assay at a penicillin concentration of 2 or $10 \mu \mathrm{g} / \mathrm{ml}$ but not at $0.25 \mu \mathrm{g} / \mathrm{ml}$ and the cell-lysis assay, the $\beta$-lactamase disk method, the replication method and traditional $\mathrm{MBC} / \mathrm{MIC}$ measurements of cultures in the mid-logarithmic phase.

\section{Discussion}

Tolerance is the resistance characterised by a decrease in the bactericidal effect of $\beta$-lactam antibiotics, as measured by $\mathrm{MBC}$ determinations. ${ }^{19}$ Both macrodilution and microdilution methods for the assessment of the $\mathrm{MBC}$ are susceptible to several technical problems which make assessments of the $\mathrm{MBC}$ poorly reproducible. ${ }^{4,7,20}$ It has been shown, in this study and by others, ${ }^{12.13}$ that technical factors are of the utmost importance. In this study the macrobroth MIC method, full 24-h incubation of the tubes, gentle shaking of MIC tubes $4 \mathrm{~h}$ before MBC plating and the use of $\beta$-lactamase to prevent carry-over of penicillin $^{20,21}$ were applied. Moreover, the fact that it is essential to obtain the desired phase of growth for each individual strain may be overlooked.

In this study two types of penicillin-tolerant $S$. pyogenes strains were identified by the MBC/MIC for mid-logarithmic and stationary phases. The results of all methods for one set of strains were positive. MBC measurements were not influenced by the phase of growth and the bactericidal assays for these strains gave cell counts that did not decrease by more than $2 \log _{10}$ within $6 \mathrm{~h}$. These strains were described as "highly tolerant". The other set of strains showed an increased rate of killing in the rapidly growing phase, resulting in $\mathrm{MBC} / \mathrm{MIC}$ ratios of at least 32 only in the stationary phase. These latter strains were called "moderately tolerant".

Among the strains classically defined as tolerant to penicillin, there can be wide variations in the reduction of bacterial counts, from almost $3 \log _{10}$ to $<1 \log _{10} \cdot{ }^{9,10,11}$ For Staphylococcus aureus ${ }^{9}$, $S$. pyogenes ${ }^{10}$ and viridans streptococci ${ }^{11}$ it has been postulated that the percentage of surviving cells following incubation with an antibiotic reflects the bactericidal effects of penicillin more accurately than the MBC. In the present study penicillin-tolerant strains of both groups had equal $\mathrm{MBC} / \mathrm{MIC}$ ratios and there was no significant difference in their degree of tolerance. In the stationary phase of growth the tolerance percentage was higher for one strain only. Unfortunately, moderately-tolerant $S$. pyogenes strains cannot be detected by $\mathrm{MBC} / \mathrm{MIC}$ measurements of mid-logarithmic cultures. The identification of penicillin-tolerant strains on the basis of stationary phase growth cultures only is often associated with persistent organisms. For staphylococci, correlations with phenotypic but not genotypic tolerance or with persistent organisms have been described, ${ }^{\mathbf{6}, 22-24}$ but this is probably species-dependent. We suggest that moderate tolerance in group A streptococci should be 
regarded as true tolerance because these strains had a non-lytic response in the cell-lysis assay. Slow lysis of tolerant strains may be caused by low levels of autolytic enzyme activity, as in some other species. ${ }^{25.26}$ Similar studies of $S$. pyogenes, as well as studies of the patterns of penicillin-binding proteins, are still lacking and further investigations on these aspects are required.

The paradoxical phenomenon, or Eagle effect, ${ }^{27.28}$ in which the survival rate for a strain is lowest at penicillin concentrations immediately above the MIC, was observed in $\mathrm{MBC}$ determinations as well as for the kill assay but not for the cell-lysis assay.

Both groups of tolerant strains were positive according to the $\beta$-lactamase disk method and the replication method, both of which have been described as being useful in the detection of tolerance. ${ }^{16-18}$

Tolerance was established on penicillin gradient plates. Non-tolerant strains did not survive consecutive transfer, whereas tolerant strains could be rep-

\section{References}

1. Dagan R, Ferne M. Association of penicillin-tolerant streptococci with epidemics of streptococcal pharyngitis in closed communities. Eur J Clin Microbial Infect Dis 1989; 8: 629631 .

2. Grahn E, Holm SE, Roos K. Penicillin tolerance in betastreptococci isolated from patients with tonsillitis. Scand $J$ Infect Dis 1987: 19: 421-426.

3. Sherris JC. Problems in in vitro determination of antibiotic tolerance in clinical isolates. Antimicrob Agents Chemother 1986; 30: 633-637

4. Woolfrey BF, Lally RT, Gresser-Burns M. Penicillin tolerance in group A streptococci. $J$ Infect Dis $1988 ; 158: 487-488$.

5. Mayhall CG, Apollo E. Effect of storage and changes in bacterial growth phase and antibiotic concentrations on antimicrobial tolerance in Staphylococcus aureus. Antimicrob Agents Chemother 1980; 18: 784788 .

6. Tuomanen E. Phenotypic tolerance: the search for beta-lactam antibiotics that kill nongrowing bacteria. Rev Infect Dis 1986; 8: Suppl 3: S279-S291.

7. James PA. Comparison of four methods for the determination of MIC and MBC of penicillin for viridans streptococci and the implications for penicillin tolerance. $J$ Antimicrob Chemother $1990 ; 25$ : 209-216.

8. Sabath LD, Wheeler N, Laverdiere M, Blazevic D, Wilkinson BJ. A new type of penicillin resistance of Staphylococcus aureus. Lancet 1977; 1: 443-447.

9. Goessens WHF, Fontijne $P$, Van Raffe $M$, Michel MF, Tolerance percentage as a criterion for the detection of tolerant Staphylococcus aureus strains. Antimicrob Agents Chemother 1984; 25 : 575-578.

10. Michel MF, Van Leeuwen WB. Degree and stability of tolerance to penicillin in Streptococcus pyogenes. Eur J Clin Microbio Infect Dis $1989 ; 8: 225-232$

11. Meylan PR, Francioli P, Glauser MP. Discrepancies between $\mathrm{MBC}$ and actual killing of viridans group streptococci by cell-wall active antibiotics. Antimicrob Agents Chemother $1986 ; 29: 418-423$

12. Taylor PC, Schoenknecht FD, Sherris JC, Linner EC. Determination of minimum bactericidal concentrations of oxacillin for Staphylococcus aureus: influence and significance of technical factors. Antimicrob Agents Chemother 1983; 23: $142-150$.

13. Woolfrey BF, Lally RT, Ederer MN. Influence of technical factor variations during inoculum preparation on the agar dilution plate-count method for quantitation of Staphylococcus aureus oxacillin persisters. Antimicrob Agents Chemother 1986; 30: 792-793. licated up to 15 times. Staphylococci ${ }^{19}$ and streptococci, ${ }^{11}$ " may lose their penicillin tolerance after storage at $20^{\circ}, 4^{\circ}$ and $-70^{\circ} \mathrm{C}$ but usually not when first lyophilised. In our experience the MBC/MIC ratios for the stationary phase of growth did not reflect loss of penicillin tolerance after storage, in contrast to those for the mid-logarithmic phase (fig. 5). The tolerance of mid-logarithmic cultures could be restored by consecutive transfer to penicillin gradients. ${ }^{10}$ During this process the tolerance percentage of highly tolerant strains increased slowly.

We have shown that assays of cultures in the midlogarithmic phase can fail to detect moderatelytolerant strains of $S$. pyogenes.

The authors acknowledge the technical help of T. J. K van der Reijden, the stimulating support and discussions of Dr E. M. Veringa and the statistical help of Dr F. Kok and H. Franken. We thank Professor C. P. A. van Boven for reading this manuscript and G. P. Bieger-Smith for assistance with the English language. We are grateful for the strains provided by M. F. Michel, K. S. Kim and K. Krasinski.

14. Lakshmi TM, Kim KS. A mutant of group A streptococcus resistant to high levels of kanamycin exhibits characteristics of penicillin tolerance in vitro. FEMS Microbiol Lett 1988; 55: $93-98$.

15. Krasinski K, Hanna B, LaRussa P, Desiderio D. Penicillin tolerant group A streptococci. Diagn Microbiol Infect Dis $1986 ; 4: 291-297$.

16. Dankert J, Holloway Y, Joldersma W, Hess J. Screening for penicillin tolerance in viridans streptococci by a simple disk method. $J$ Clin Microbiol 1982; 16: 744-746.

17. Slater GJ, Greenwood D. Detection of penicillin tolerance in streptococci. J Clin Pathol 1983; 36: 1353-1356.

18. Kim KS, Anthony BF. Use of penicillin-gradient and replicate plates for the demonstration of tolerance to penicillin in streptococci. J Infect Dis $1983 ; 148: 488-491$.

19. Sabath LD, Mokhbat JE. What is the clinical significance of tolerance to $\beta$-lactam antibiotics? In: Remington JS, Schwarz MN (eds) Current clinical topics in infectious diseases. New York, McGraw-Hill Book Company. 1983: 358-377.

20. Stratton $\mathbf{C W}$. The role of the microbiology laboratory in the treatment of infective endocarditis. $J$ Antimicrob Chemother $1987 ; 20$ Suppl A : 41-49.

21. Goessens WHF, Fontijne P. Michel MF. Factors influencing detection of tolerance in Staphylococcus aureus. Antimicrob Agents Chemother 1982; 22: 364-368.

22. Gilbert P, Collier PHJ, Brown MRW. Influence of growth rate on susceptibility to antimicrobial agents: biofilms, cell cycle, dormancy, and stringent response. Antimicrob Agents Chemother 1990; 34: 1865-1868.

23. Greenwood D. Phenotypic resistance to antimicrobial agents. $J$ Antimicrob Chemother 1985; 15: 653-658.

24. Woolfrey BF, Lally RT, Ederer MN. Evaluation of oxacillin tolerance in Staphylococcus aureus by a novel method. Antimicrob Agents Chemother 1985; 28: 381-388.

25. Said I, Fletcher H, Volpe A, Daneo-Moore L. Penicillin tolerance in Streptococcus faecium ATCC 9790. Antimicrob Agents Chemother 1987; 31:1150-1152.

26. Moreillon PH, Markiewicz Z, Nachman S et al. Two bactericidal targets for penicillin in pneumococci: autolysisdependent and autolysis-independent killing mechanisms. Antimicrob Agents Chemother 1990; 34: 33-39.

27. Eagle $H$, Musselman AD. The rate of bactericidal action of penicillin in vitro as a function of its concentration and its paradoxically reduced activity at high concentrations against certain organisms. $J$ Exp Med 1948; 88: 99-131.

28. Shah PM. Paradoxical effect of antibiotics. I. The "Eagle effect". J Antimicrob Chemother 1982; 10: 259-260. 